\title{
LIGHT AND TRANSMISSION ELECTRON MICROSCOPICAL CHANGES ASSOCIATED WITH LEIURUS QUINQESTRIATUS VENOM IN RABBITS
}

\author{
Salah H. Afifi ${ }^{1}$, Reham El-Kashef ${ }^{2}$, A. Sh. Seddek ${ }^{2}$, Diefy A. Salem ${ }^{1}$ \\ ${ }^{1}$ Department of Pathology, Faculty of Veterinary Medicine, \\ Assiut University, Assiut, Egypt \\ ${ }^{2}$ Department of Forensic Medicine and Toxicology, Faculty of Veterinary Medicine, \\ South Valley University, Kena, Egypt
}

Received 10 July 2015; Received in revised form 11 October 2015; Accepted 19 November 2015

\begin{abstract}
Thirty California female rabbits were obtained from the Animal Care Center, College of Agriculture, South Valley University and acclimated to laboratory conditions for one week. The Leiurus quinquestriatus (LQ) venom was collected from mature scorpions by electrical stimulation of the telson. A single dose of crude venom of $0.4 \mathrm{ml} / \mathrm{kg}$ (diluted in normal saline with a ratio of 1:1) was injected into a peripheral ear vein. The lungs, brains, hearts, kidneys, were sampled and fixed in $10 \%$ formalin from rabbits sacrificed at zero, 30 minutes, $1 \mathrm{hr}$, and $4 \mathrm{hrs}$, post-envenomation (three animals at each sacrifice). Respiratory distress and neurological manifestations were the main clinical signs. Congestion of the lungs was started at one hour postenvenomation. Vascular changes including hyperemia and hemorrhage were also observed till 24 hours post-envenomation. The main histopathological changes of the lungs were edema, hemorrhage, emphysema, and eosinophilic bronchitis. Transmission electron microscopy revealed several eosinophils with abundant granules and breakdown of their membranes suggesting degranulation. The cerebrum showed malacia and edema. Myocardial damage expressed by focal area of myolysis at half-hour post-envenomation and interstitial edema by at 1 , and 4 hour post-envenomation was also evident. In conclusion, scorpion venom induced consistent and relevant histopathological changes in all examined organs.
\end{abstract}

Key words: Leiurus quinqestriatus venom, rabbits, light and transmission electron microscopy

\section{INTRODUCTION}

Scorpion stings are a major public health and veterinary problem in tropical and subtropical countries. Most of the scorpions that are dangerously venomous to humans and animals belong to the buthidae. The reported $\mathrm{LD}_{50}$ of Leiurus quinquestriatus (L.Q.) venom is ranged from $0.16-0.5 \mathrm{mg} / \mathrm{kg}$ in different animals (1). The voltage dependent ion channels, sodium, potassium and calcium channels are the main targets of scorpion venom action. The symptoms of scorpion envenomation result from a complex interaction

Corresponding author: Dr. Salah H. Afifi, $\mathrm{PhD}$

E-mail address: afifi s 4@hotmail.com

Present address: Department of Pathology, Faculty of Veterinary

Medicine, Assiut University, Assiut, Egypt

Phone: +0100829295

Copyright: (C) 2015 Afifi S.H. This is an open-access article published under the terms of the Creative Commons Attribution License which permits unrestricted use, distribution, and reproduction in any medium, provided the original author and source are credited.

Competing Interests: The authors have declared that no competing interests exist.

Available Online First: 27 November 2015

Published on: 15 March 2016

http://dx.doi.org/10.1515/macvetrev-2015-0067 of parasympathetic and sympathetic stimulation along with the release of a variety of endogenous compounds i.e. catecholamines, angiotensin II, glucagon, corticosteroids, bradykinins. Fatalities are primarily the result of cardiovascular and respiratory dysfunction and failure (2). L. Q. scorpion is one of the most important members of the buthidae family. It is reported as one of the most dangerous scorpions in the world. This is because its venom is a powerful cocktail of neurtoxins with a low $\mathrm{LD}_{50}$ (3). The reported $\mathrm{LD}_{50}$ of L.Q. venom is ranged from $0.16-0.5 \mathrm{mg} / \mathrm{kg}$ in different animals which confirm the severity of this species of scorpion (1).

The objective of this study is to investigate in vivo the pathological changes associated with Leiurus quinquestriatus crude venom injection on female rabbits.

\section{MATERIAL AND METHODS}

A number of 30 California female rabbits (1.5$2.4 \mathrm{~kg}$ ) were obtained from the Animal Care Center, College of Agriculture, South Valley University. 


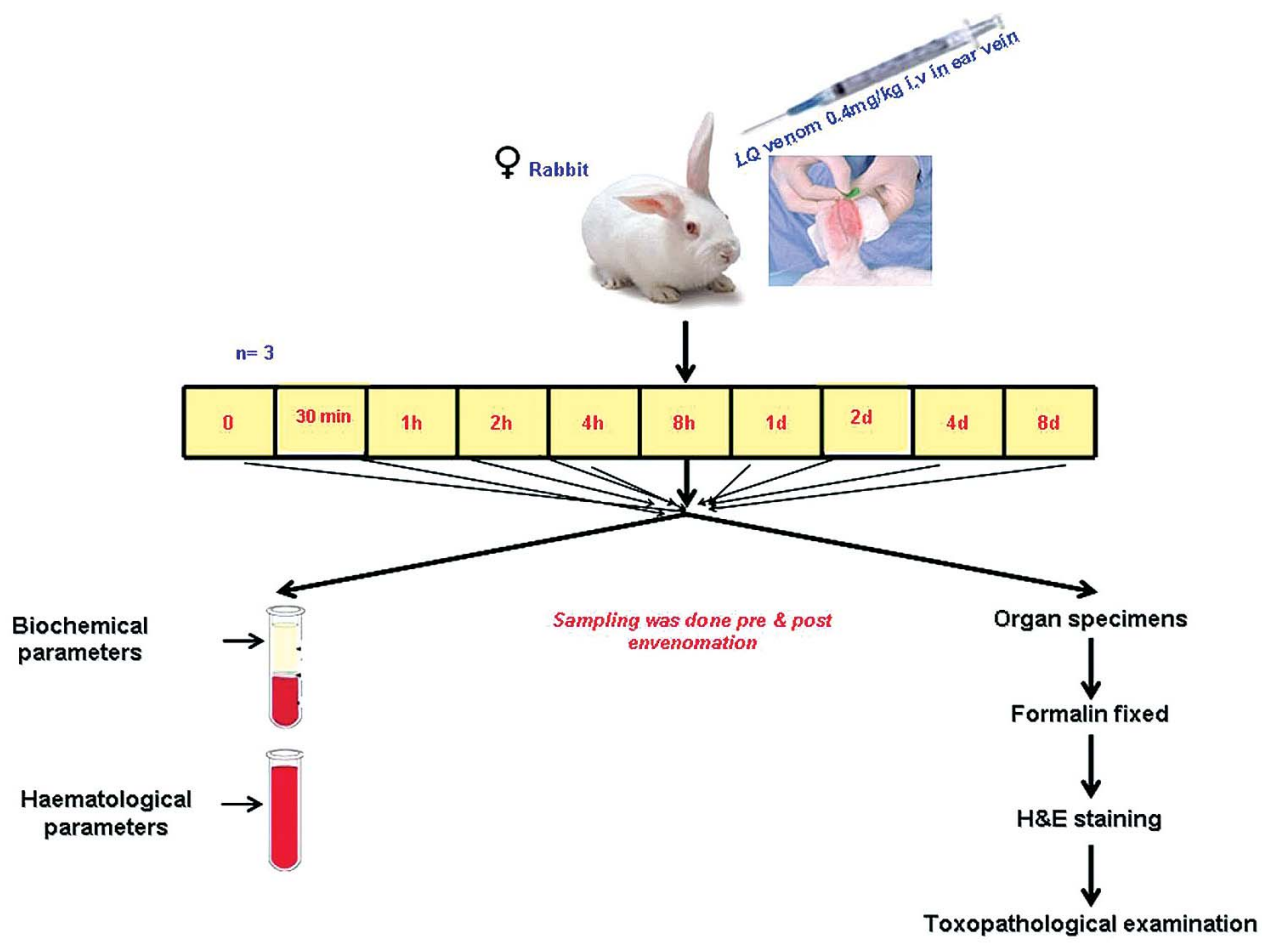

Figure 1. Experimental design in the current study

Animals were housed under specific pathogen free condition with water and feed ad libitum. The animals were kept under observation for one week prior to the start of treatment for acclimatization.

A single dose of crude L.Q. venom of $0.4 \mathrm{mg} / \mathrm{kg}$ was injected i.v. in the peripheral ear vein. The venom was diluted in normal saline with a ratio 1:1. Samples collected in a time course started from 0 up to 8 days post injection as shown in Fig. 1 .

Rabbits were anaesthetized by chloroform and post mortem examination was carried out. For histopathological examination 3 animals were used per time point $(n=3)$ and sampling done pre and post envenomation.

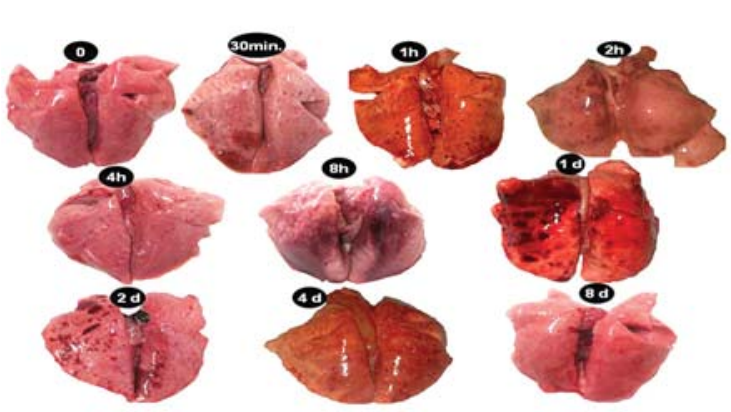

Figure 2. Gross appearance of rabbit's lungs at different intervals of envenomation, as well as the non-exposed rabbits

\section{RESULTS}

Grossly, wide spread of congestion all over the body organs was observed including lungs, heart, brain, liver, stomach, intestine, kidneys, spleen, ovary and fallopian tube. The lung and brain appeared to be the most affected organs. The lungs showed time dependent congestion and petechial hemorrhage with peak at Day 1. By Day 8 post injection, the lungs look similar to the control (Fig. 2).

The lungs exposed to administration of scorpion poison via I.V. route and collected at $0.5 \mathrm{~h}$ showed marked alveolar emphysema and damage of the bronchiolar epithelium (Fig. 4) compared to the control at zero time (Fig. 3). The lungs at $1 \mathrm{~h}$ post exposure had the previous changes observed at $0.5 \mathrm{~h}$ beside interstitial hemorrhage (Fig. 5). Moreover, focal area of consolidation was observed. The lungs collected at $4 \mathrm{~h}$ showed more advanced changes of the lung tissues which were observed in this time interval. This change was expressed by perivascular inflammatory cellular reaction mainly of eosinophils (Fig. 6).

Transmission electron microscopy proved these eosinophils with abundant dense granules in their cytoplasm, as well as the breakdown of its membranes (Fig. 7 and Fig. 8). 


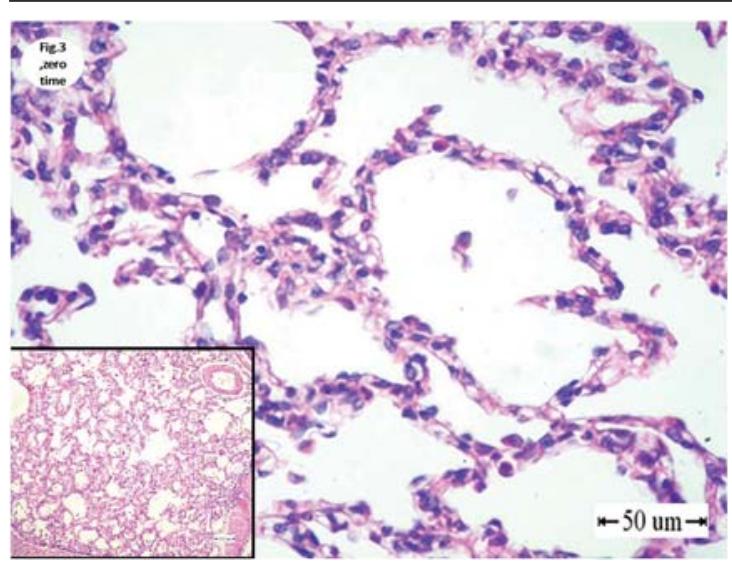

Figure 3. Lung of rabbits collected at Zero hour postexposure showing the normal appearance of alveoli. Bar $=50 u m$.

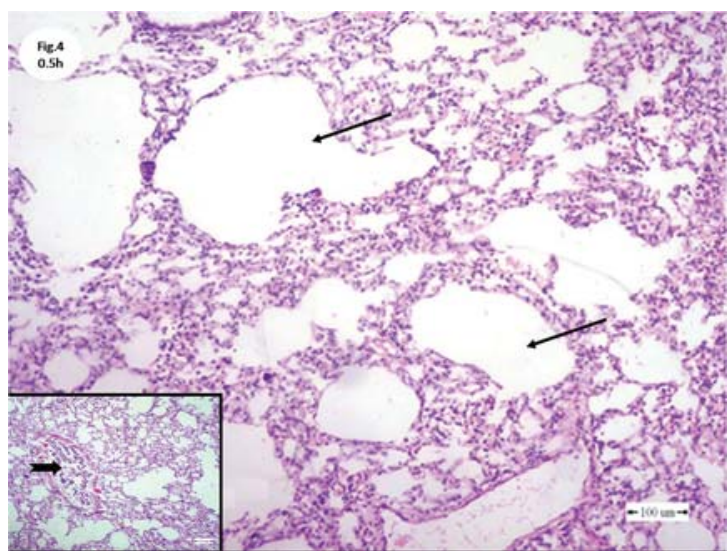

Figure 4. Lung of rabbits collected at half hour postexposure to Scorpion poison showing well expressed alveolar emphysema (arrow) and damage of bronchiolar epithelium. H\&E; bar $=100 \mu \mathrm{m}$

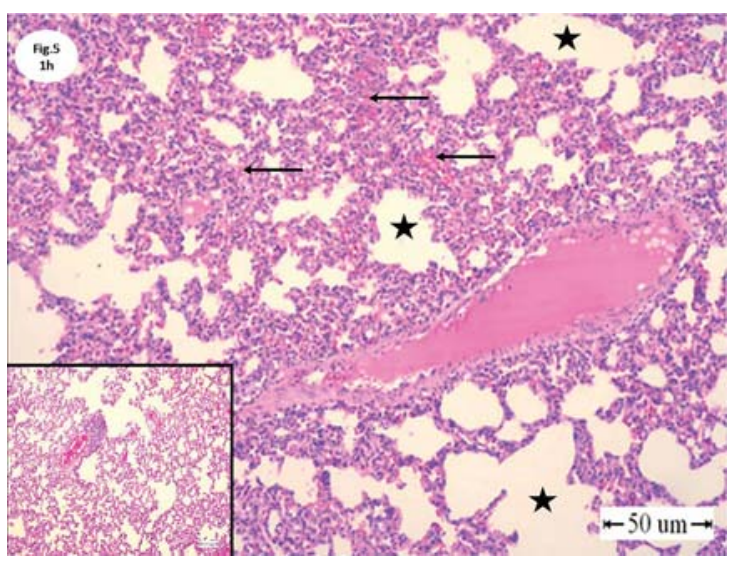

Figure 5. Lung of rabbits collected at 1 hour post-exposure to Scorpion poison showing alveolar emphysema (star) and interstitial hemorrhage (arrow). $\mathrm{H} \& \mathrm{E}$; bar $=50 \mu \mathrm{m}$

The brain collected at $0.5 \mathrm{~h}$ post-envenomation had focal area of malacia. This area showed the feature of liquefactive necrosis (Fig. 10). The brains of rabbits at $1 \mathrm{~h}$ post-exposure showed marked edema which is expressed by vacuolation (Fig. 11). While, the brains collected at $4 \mathrm{~h}$ had well-defined edema (Fig. 12) compared to the brains collected at zero time (Fig. 9).

The hearts of rabbits collected at half hours showed severe myocardiolysis (Fig. 14). While at 1 , and 4 hours, the hearts showed marked interstitial edema (Fig. 15) compared to the hearts collected at zero time (Fig. 13).

The kidneys collected at half and 1 hour showed focal necrosis of tubular epithelium (Fig. 17). While kidneys of rabbits collected at 4 hours postexposure to Scorpion poison showed well expressed interstitial hemorrhage and necrosis of the tubular epithelium (Fig. 18) compared to the kidneys collected at zero time (Fig. 16).

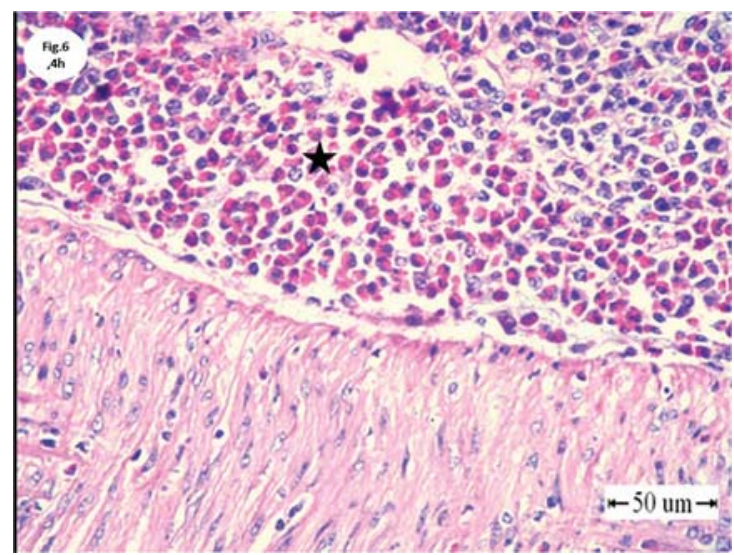

Figure 6. Lung of rabbits collected at 4 hours postexposure to Scorpion poison showing eosinophilic bronchitis (star). H\&E; bar $=50 \mu \mathrm{m}$

\section{DISCUSSION}

Leiurus quinquestriatus was recorded to be the most dangerous scorpion in the world. This is due to complex venom composition particularly the potent neurotoxins:chlorotoxin and charbydotoxin (4). Scorpion venom is known to be fatal and produces several alterations in different organs of the body. Alterations in respiratory system components lead to altered lung mechanics, characterized by histological abnormalities, edema, hemorrhage, inflammation and increased deposition of matrix extra-cellular proteins (5). There are several reports indicating that the venom caused well-expressed morphological changes in the lung. These changes were mainly lung edema, hemorrhage, and pneumonia $(6,7)$.

In the present study, the lung lesions start with emphysema and damage of bronchiolar epithelium at 0.5 hours followed by hemorrhage at one-hour. The lung edema and the perivascular eosinophilic 


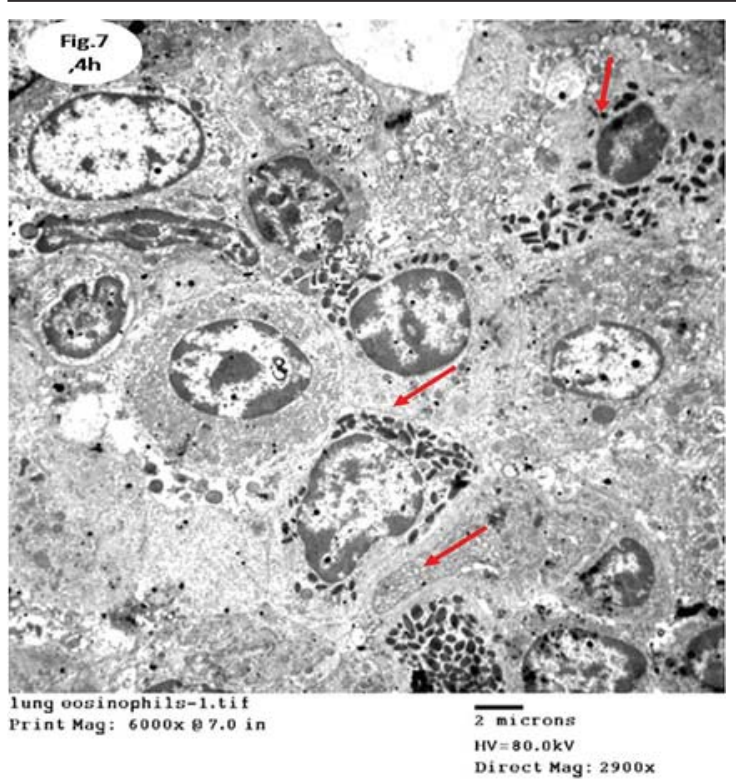

Figure 7. TEM of rabbit lung collected at 4 hours postexposure showing eosinophils with abundant dark granules. Lead citrate and uranyl acetate. Magnification $6000 \mathrm{x}$.

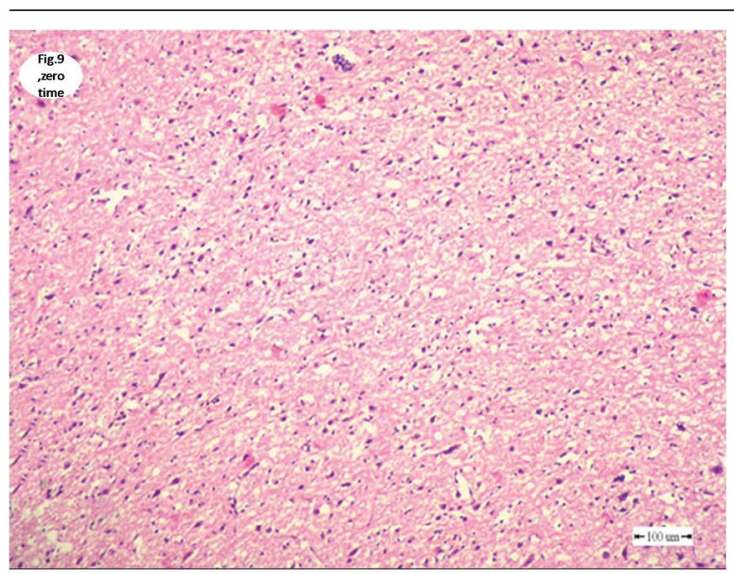

Figure 9. Brain of rabbit collected at Zero hour postexposure showing the normal appearance of cerebrum. $\mathrm{H} \& \mathrm{E} ; \mathrm{bar}=100 \mu \mathrm{m}$

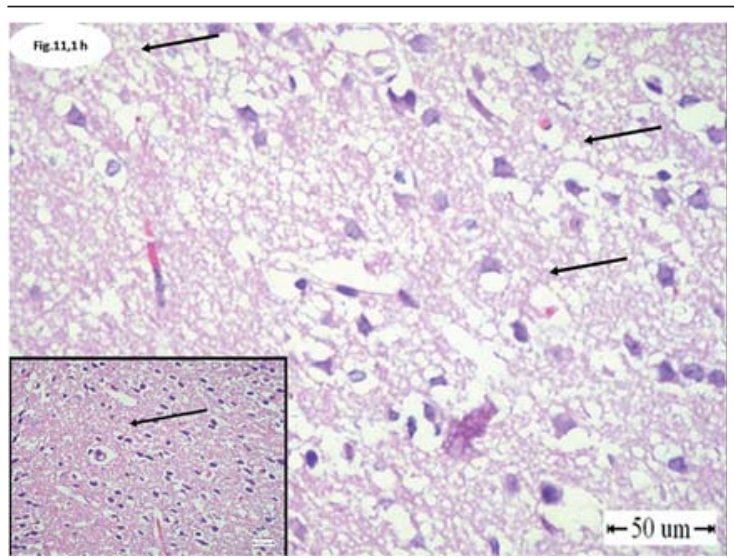

Figure 11. Brain of rabbits collected at 1 hour postexposure to Scorpion poison showing marked edema which appeared as clear well defined vacuoles (Moutheaten, arrow). H\&E; bar $=100 \mu \mathrm{m}$

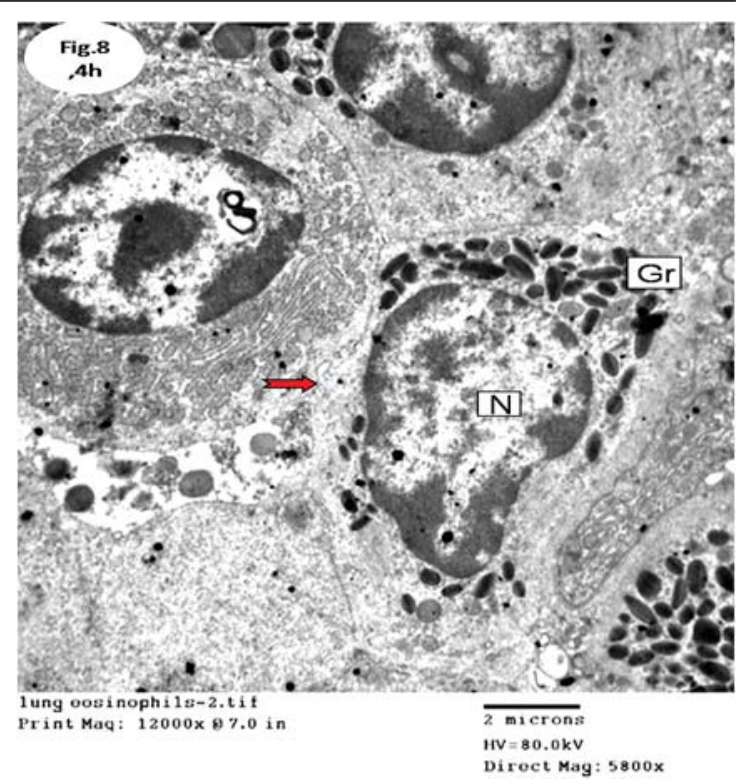

Figure 8. TEM of rabbit lung collected at 4 hours postexposure showing breakdown of eosinophil membranes. Lead citrate and uranyl acetate. Magnification $12000 \mathrm{x}$.

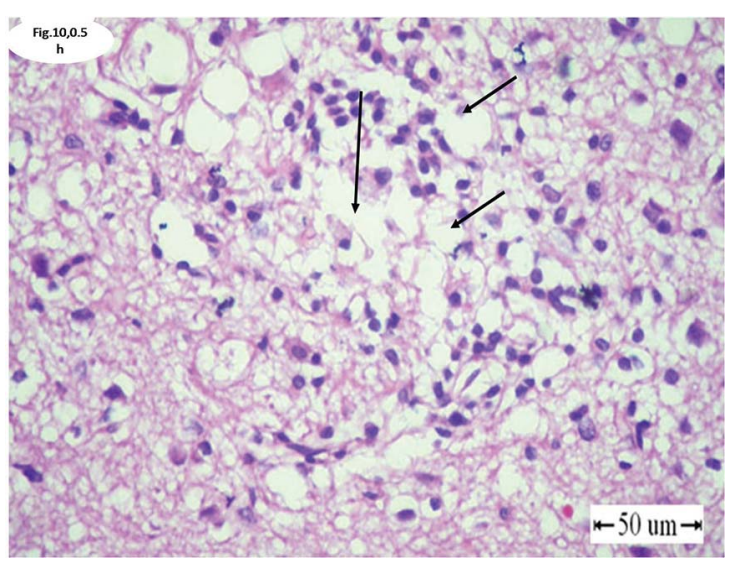

Figure 10. Brain of rabbits collected at half hour postexposure to Scorpion poison showing liquefactive necrosis (arrow). H\&E; bar $=100 \mu \mathrm{m}$

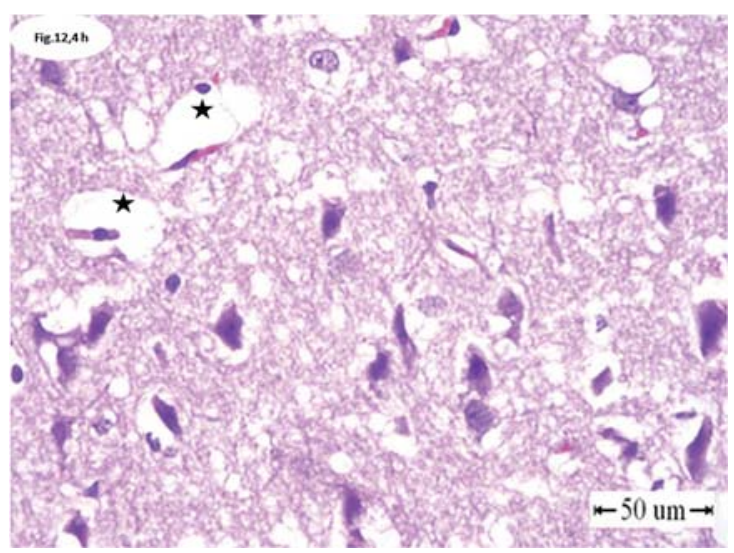

Figure 12. Brain of rabbits collected at 4 hour postexposure to Scorpion poison showing well-defined edema. H\&E; bar $=100 \mu \mathrm{m}$ 


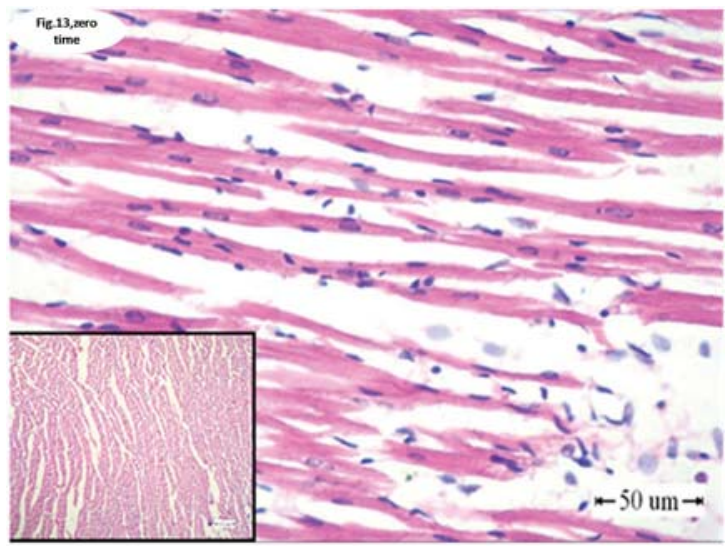

Figure 13. Heart of rabbit collected at Zero hour postexposure showing the normal appearance of myocardium. $\mathrm{H} \& \mathrm{E} ; \mathrm{bar}=100 \mu \mathrm{m}$

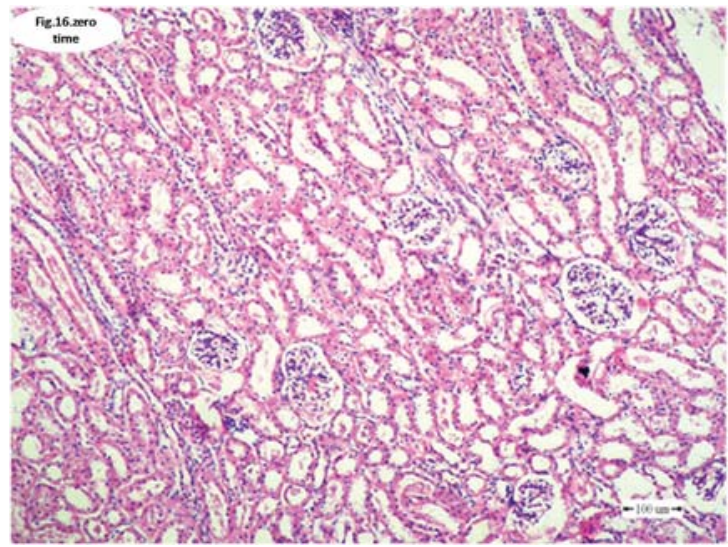

Figure 16. kidney of rabbit collected at Zero hour postexposure showing the normal appearance of glomeruli, tubules, and interstitial tissues. H\&E; bar $=100 \mu \mathrm{m}$

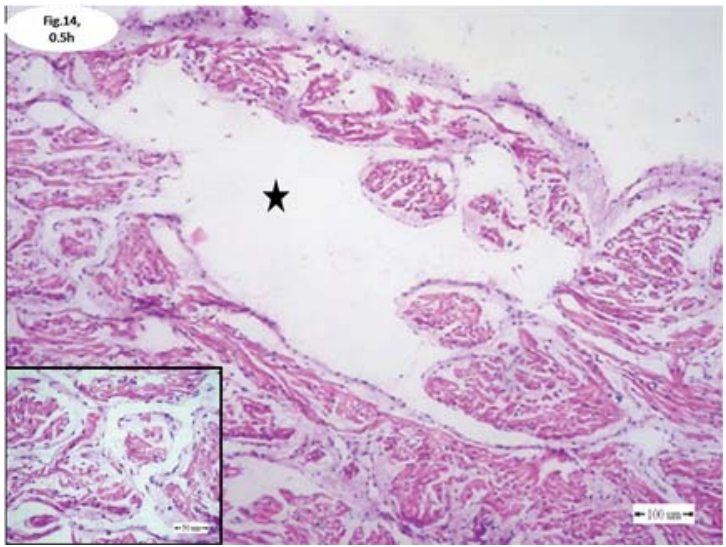

Figure 14. Heart of rabbits collected at half hour postexposure to Scorpion poison showed focal area of sever myocardiao- lysis (star). H\&E; bar $=100 \mu \mathrm{m}$

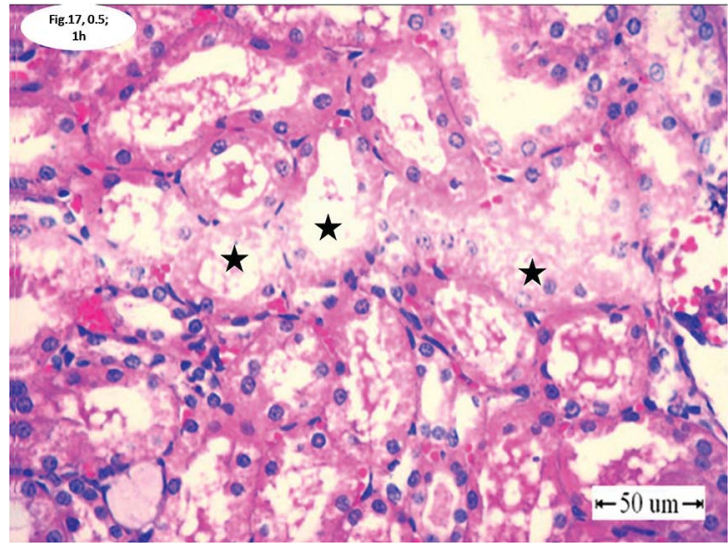

Figure 17. kidney of rabbit collected at half \& 1 h postexposure to Scorpion poison showing focal necrosis of tubular epithelium (stars). H\&E; bar $=100 \mu \mathrm{m}$

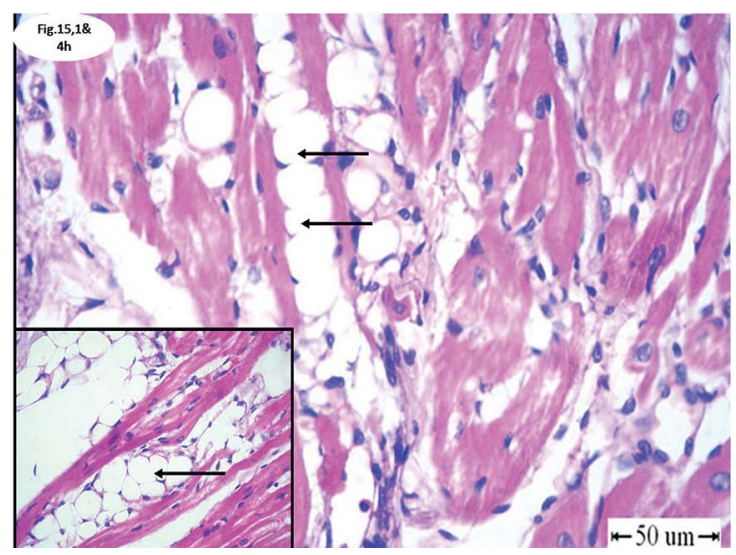

Figure 15. Hearts of rabbits collected at 1 and 4 hours post-exposure to Scorpion poison showed marked Interstitial edema (arrows). H\&E; bar $=100 \mu \mathrm{m}$

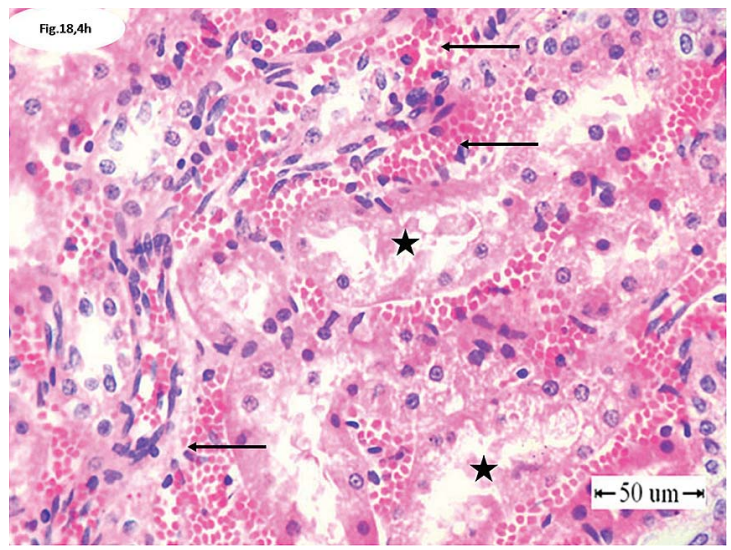

Figure 18. Kidneys of rabbits collected at 4 hours postexposure to Scorpion poison showing well expressed interstitial hemorrhage (arrow) and necrosis of tubular epithelium (star). H\&E; bar $=100 \mu \mathrm{m}$ 
accumulation in the lung tissue were observed at four hours. These changes were previously described $(6,7)$. The lung edema is considered to be the main morphological change due to the venom of scorpion such as Tityus serrulatus, one of the most venomous scorpions. Its venom is made up of water-soluble and water-insoluble proteins, among which tityus toxin are the most toxic component (8). Transmission electron microscopy in the present study proved the appearance of eosinophils and suggested degranulation of its content had occurred and attributed to the respiratory distress observed clinically.

The present study showed a focal area of malacia characterized by liquifactive necrosis at 0.5 hour. This result may suggest that the toxin of this species has a strong effect within short time, especially with the route of inoculation (i.v). It is known that the scorpion toxins bind to neurotoxin receptor sites blocking sodium channel inactivation or potassium channels. The binding to these channel receptors increases the depolarization time of the channel and consequently, induces excessive neurotransmitter release resulting in the brain damage (9).

Myocardial toxicity is considered one of the major causes of death beside respiratory failure, especially in children stung by the scorpion venom. Scorpion venoms is known to stimulate branches of autonomic nerves with subsequent release of catecholamines (10). Reversible myocardial injury has been attributed to the release of a marker known as Cardiac Tropnin I (CT1), while irreversible injury of the heart may be attributed to the release of CT1 resulting from the damaged myocardial cells $(10,11$, $12,13)$. In the present study, irreversible myocardial damage expressed by necrosis was observed only at half-hour. This result may suggest an immediate effect of the venom (toxins produced by the species used in the study).

The nephrotoxic effect of scorpion venoms has been documented. Mansour et al. (14) described the microscopic appearance of renal tissues of rats envenomed with the toxin of L.Q scorpion. The study revealed dose and time-dependent pathological changes including glomerular congestion at early stages of envenoming developing to glomerular hypertrophy and hypercellularity followed by mesangiolysis. The epithelial cells of the renal tubules were severely swollen and suffered from necrobiotic changes or cellular damage and their lumina contained eosinophilic masses or hyaline casts.

The present study at half-hour showed necrosis of the glomerular tuft, which is expressed by disappearance of most of the lining epithelium namely mesengial, endothelial, and pericytes cells.
Focal area of severe necrosis of the kidney tubular epithelium, sever inter-tublar hemorrhage by onehour post-evenomnation, interstitial hemorrhage of the kidney was noticed as well as necrosis of the tubular epithelium lining by four-hours. These results were similar to those reported by Mansour et al. (14).

\section{CONCLUSION}

In conclusion, respiratory distress could be due to eosinophilic bronchitis observed by both light and transmission electron microscope. Irreversible myocardial damage expressed by necrosis and edema was evident in this study. Nephrotoxicity was also evident. Scorpion venom is a hazard to human beings due to its effect on the lungs, brains, hearts and kidneys.

\section{REFERENCES}

1. Gueron, M., Ilia, R., Sofer, S. (1992). The cardiovascular system after scorpion envenomation. A review. J Toxicol Clin Toxicol. 30 (2): 245 - 258. http://dx.doi.org/10.3109/15563659209038636 PMid: 1588674

2. Cupo, P., Figueiredo, A. B., Filho, A. P., Pintya, A. O., Tavares, G.A., Caligaris, F. (2007). Acute left ventricular dysfunction of severe scorpion envenomation is related to myocardial perfusion disturbance. Int J Cardiol. 116 (1): 98 - 106. http://dx.doi.org/10.1016/j.ijcard.2006.02.015 PMid:16828898

3. Ross, L. K. (2008). Leiurus quinquestriatus (Ehrenberg, 1828). The Scorpion Files. http://www.ntnu.no/ub/scorpion-files/1_ quinquestriatus_info.pdf

4. Debin, J. A., Strichartz (1991). Chloride channel inhibition by the venom of the scorpion Leiurus quinquestriatus. Toxicon. 29, $1403-1408$. http://dx.doi.org/10.1016/0041-0101(91)90128-E

5. Santos, F. B., Nagato, L. K., Boechem, N. M., Negri, E. M., Guimara ${ }^{2}$ es, A., Capelozzi, V. L., Faffe, D. S., Zin, W. A., Rocco, P. R. (2006). Time course of lung parenchyma remodeling in pulmonary and extra-pulmonary acute lung injury. J Appl Physiol (1985) 100(1): $98-106$.

http://dx.doi.org/10.1152/japplphysiol.00395.2005 PMid:16109834

6. De Matos, I. M., Rocha, O.A., Leite, R., Freire-Maia, L. (1997). Lung oedema induced by Tityus serrulatus scorpion venom in the rat. Comp Biochem Physiol C Pharmacol Toxicol Endocrinol. 118 (2): 143 - 148. http://dx.doi.org/10.1016/S0742-8413(97)00086-8 
Leiurus quinqestriatus venom in rabbits - Light and TEM changes

7. Paneque Peres, A. C., Nonaka, P. N., de Carvalho, T., Toyama,M.H., Silva,C.A., Vieira, R.P.,Dolhnikoff,M., Zamuner, S. R., de Oliveira, L. V. (2009). Effects of Tityus serrulatus scorpion venom on lung mechanics and inflammation in mice. Toxicon. 53 (7 - 8): 779 - 785 .

8. Nunan, E. A., Arya, V., Hochhaus, G., Cardoso, V. N., Moraes-Santos, T. (2004). Age effects on the pharmacokinetics of tityustoxin from Tityus serrulatus scorpion venom in rats. Braz. J. Med. Biol. Res. 37, $385-390$.

http://dx.doi.org/10.1590/S0100-879X2004000300016 PMid:15060708

9. Carvalho, F. F., Nencioni, A. L., Lebrun, I., Sandoval, M. R., Dorce, V. A. (1998). Behavioral, electroencephalographic, and histopathologic effects of a neuropeptide isolated from Tityus serrulatus scorpion venom in rats. Pharmacol Biochem Behav. 60 (1): 7 - 14

http://dx.doi.org/10.1016/S0091-3057(97)00407-3

10. Bakir, F., Ozkan, O., Alcigir, M. E., Vural, S. A. (2012). Effects of Androctonus crassicauda scorpion venom on the heart tissue. Journal of animal and veterinary advances $11,2594-2599$

http://dx.doi.org/10.3923/javaa.2012.2594.2599
11. Chue, W. W., Dieter, R. S., Stone, C. K. (2002). Evolving clinical applications of cardiac markers: A review of the literature. WMJ. 101, 49 - 55.

12. Correa, M. M., Sampaio, S. V., Lopes, R. A., Mancuso, L. C., Cunha, O. A., Franco, J. J., Giglio, J. R. (1997). Biochemical and histopathological alterations induced in rats by Tityus serrulatus scorpion venom and its major neurotoxin Tityustoxin-I. Toxicon. 35, $1053-1057$. http://dx.doi.org/10.1016/S0041-0101(96)00219-X

13. Ibrahim, H. A., Nabil, Z. I., Abdel-Rahman, M. S. (1996). Effect of scorpion Leiurus quinquestriatus (H\&E) venom on the electrophysiology of mammalian heart. III-Blood biochemical studies. J. Egypt Ger. Soc. Zool. 21, 309 - 312.

14. Mansour, N. M., Tawfik, M. N., Rahmy, T. R., Yaseen, A. E. (2007). Protective effect of Ambrosia maritima plant extract against renal alterations induced by Leiurus quinquestriatus scorpion envenoming. Egyptian journal of natural toxins 4 (2): 101 -130.

Please cite this article as: Afifi S.H., El-Kashef R., Seddek A. Sh., Salem D.A. Light and transmission electron microscopical changes associated with Leiurus quinqestriatus venom in rabbits. Mac Vet Rev 2016; 39 (1): 51-57.

http://dx.doi.org/10.1515/macvetrev-2015-0067 